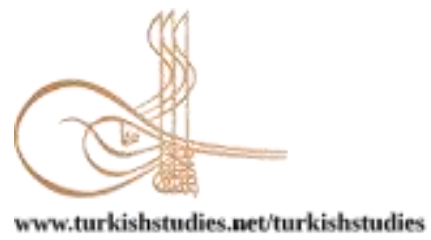

Turkish Studies

\title{
Elit Karate Sporcularında İmgeleme ve Kaygı İlişkisinin İncelenmesi*
}

\author{
Investigation of the Relationship between Imagination and Anxiety in Elite Karate Athletes
}

\author{
Emre Boz* - Murat $\mathrm{Kul}^{* *}$
}

\begin{abstract}
The main purpose of this research is to examine the relationship between the visualization uses and constant anxiety levels of elite karate athletes. The sample group of the study consists of 120 [ $\mathrm{n}_{(\mathrm{male})}=61$, $\mathrm{n}_{\text {(female) }}=59$ ] elite karate athletes determined by random sampling method. In the research, "Imagination Inventory" and "Trait Anxiety Inventory" were used as data collection tools. These variables were tested by parametric tests and Pearson Moments Product Correlation (r) Coefficient technique was used to determine the relationship between them. According to the results of the research, significant differences were found between the trait anxiety total score and "Motivational Special Imagery" sub-dimension related to the competition area variable. There was a significant difference between the maternal education level of the participants and the sub-dimensions of "Motivational General-Arousal" and "Motivational General-Mastery". A low level of significant relation was found in the trait anxiety total score and the "Cognitive Imaging" subdimension, which is one of the visualization inventory sub-dimensions in sports. As a result of the correlation analysis with the nationality class on the variables of trait anxiety total score, a low level of significant relationship was detected. As a result of the analysis related to the national class variable, it was determined that there is a low level statistically significant relationship in the "Cognitive Imaging" sub-dimension, which is one of the imagination inventory subsports in sports. As a result, it was determined that there is a low level of significant relationship between the use of visualization in elite karate athletes and the total score of trait anxiety.
\end{abstract}

Structured Abstract: Imagining a successful performance can positively affect the muscular tension and anxiety level of the athlete. It is also used to help athletes in the planning of the athlete and to overcome problems and situations that may affect the anxiety level by successfully imaging these plans. Anxiety is defined as the negative emotional state associated with the level of excitability of the nervous, nervous and inspiring body in accordance with the current conditions (Cheng, Hardy and Markland, 2009). Since anxiety is a cognitive variable, non-increase in individual doubts and performance related to performance, using the scenario in which one can effectively cope with his / her performance status can reduce anxiety (Morris, Spittle \& Watt, 2005). In this context, based on the available data, in this research; While determining the

\footnotetext{
* Bu araştırma, yüksek lisans tezinden üretilmiştir.

* Doktora Öğrencisi, Atatürk Üniversite, Kış Sporları ve Spor Bilimleri Enstitüsü

Ph.D. Student, Atatürk University, Winter Sports and Sports Sciences Institute

ORCiD https://orcid.org/0000-0001-8117-9329

emreboz94@hotmail.com

** Doç. Dr., Bayburt Üniversitesi, Beden Eğitimi ve Spor Yüksekokulu

Assoc. Prof. Dr. Bayburt University, Physical Education and Sports School

ORCiD https://orcid.org/ 0000-0001-6391-8079

muratkul@bayburt.edu.tr

Cite as/ Atıf: Boz, E., Kul, M. (2020). Elit karate sporcularında imgeleme ve kaygı ilişkisinin incelenmesi. Turkish

Studies, 15(3), 1685-1697. https://dx.doi.org/10.29228/TurkishStudies.42718

Received/Geliş: 31 March/Mart 2020

Accepted/Kabul: 20 June/Haziran 2020

Checked by plagiarism software

Copyright (C) MDE, Turkey
} 
anxiety levels of the elite karate athletes and the types of imagination they use, it is also among the main purposes to examine the relationship between these two variables.

Karate, which means unarmed struggle, literally; It is formed by the combination of empty (black) and hand (te) words (Kaya et al., 2017). Karate is a Far Eastern sport, where the level of competition is increasing exponentially and at the same time creating great professionalism. In addition, this sport has been recognized by the International Olympic Committee (IOC) as an Olympic game and was awarded for the first time in the upcoming Tokyo 2020 Olympic Games (Hartz and Moreno, 2018). There are three main areas of karate sport: kihon, kata and kumite (Alkan and Çolaklar, 2001).

Constant anxiety affects the behavior of the person with the acquired personality or the tendency of the personality to predisposition. The situation and daily life of the person can be interpreted as stress or as a tendency to perceive as stress. When anxiety is constantly experienced due to the structure, the person may feel threatened even in situations that do not pose a threat. Although he feels threatened, the person shows an unintentional and disproportionate response or involuntary response in response to state anxiety (Speilberger, 1966).

Imagination has been handled from different perspectives in many sources. Weinberg and Gould (2015) describe that imagination is actually an imitation and that all sensory phenomena experienced in real life occur in the mind. Burton and Raedeke (2008), on the other hand, defined it as creating an experience in one's mind or using senses to recreate old experiences. While White and Hardy (1998) advocate that we can create the image in our minds by experiencing the image with our sensory organs, Moran (2004) thinks that it can be perceived without feeling the imagination. Davis (2015) defines imagination as something that does not exist or is not currently perceived as having a mental picture or the ability to create a concept related to it.

\section{Material and Method}

As a data collection tool in the study; Imagining Inventory in Sports (Kızıldağ and Tiryaki, 2012) and Trait Anxiety Inventory (Öner \& Le Compte, 1983) were used. have competed at international level in this inventory athletics history have taken place in the Turkish karate national team, karate nationalities of document (A, B and C class) and having 2018-2019 season Great 120 elite who participated in the Turkey Karate Championship has been applied to the Turkish karate athletes.

\section{Imagining Inventory in Sports}

Kızldag and Tiryaki (2012) conducted the Turkish reliability and validity study of the Imagination In Sport developed by Hall, Mack, Paivio and Hausenblas (1998). As a result of the inventory study, which consisted of 5 sub-dimensions and 30 items in the original, it consists of 4 sub-dimensions and 21 items. Factor analysis was applied to the data to test the construct validity of the inventory and 4 factors explained approximately $51 \%$ of the variance. The inventory consists of four sub-dimensions. These; Cognitive Imagery (.81), Motivational Special Imagery (.80), Motivational General-Stimulation (.71) and Motivational General-Mastery (.59) (Kızıldağ and Tiryaki, 2012).

\section{Trait Anxiety Inventory}

Trait Anxiety Inventory was developed by Spielberger (1970) for the purpose of determining the trait anxiety level of the person. The Turkish translation, reliability and validity study was done by Öner and Le Compte (1983). Alpha reliability of this scale consisting of 20 items is between 0.83 and 0.87 . According to the average score, the 20-35 score range is considered as "Low trait anxiety level", 36-42 score range is "Moderate trait anxiety level" and the 43-80 score range is "High trait anxiety level" (Öner and Le Compte 1983).

\section{Results}

According to the results of the research, when the total scores obtained from the constant anxiety inventory depending on the gender variable were compared, no statistically significant difference was found between the total scores of the male and female participants. When the average scores obtained from the subdimensions of the imagination inventory in sports related to gender variable were compared, there was no statistically significant difference between the average scores of male and female participants. 
There was no statistically significant difference between the total scores of the trait anxiety inventory and the sub-dimensions of the visualization inventory in sports, depending on the sports age variable. A statistically significant difference was found between the total scores obtained from the trait anxiety inventory depending on the competition area variable. When the average scores are analyzed, it is seen that the total anxiety scores of kata athletes are higher than the kumite athletes. When the average scores obtained from the sub-dimensions of the imaging inventory in sports related to the competition area variable are examined, only the "Motivational Special Imagination" sub-dimension was found, and this difference is due to the fact that kata athletes use this sub-dimension more than the kumite athletes.

No statistically significant difference was found between the total scores of the trait anxiety inventory depending on the educational status of the participants. No statistically significant difference was found between the average scores of the participants in the sub-dimensions of the imagination in sports. No statistically significant difference was found between the total scores of the trait anxiety inventory depending on the mother education status variable. No significant difference was found in the sub-dimensions of "Cognitive Imagination" and "Motivational Special Imagery" of the imagination inventory in sports. However, a significant difference was found in the sub-dimensions of "Motivational Special Imagination" and "Motivational General Mastery". It is determined that there is a significant difference between those who have graduated from "Primary School / Secondary School" and those who have graduated from "High School" according to the maternal education level of the athletes. There was no statistically significant difference between the total scores of the trait anxiety inventory depending on the educational status of the father, and there was no statistically significant difference between the mean scores of the participants in the sub-dimensions of the visualization inventory.

A low correlation was found between the trait anxiety total scores of elite karate athletes and the "Cognitive Imagination" of the imagination inventory in sports. This relationship indicates that the participants' trait anxiety scores decreased due to the use of cognitive imaging. A low level of relation was also found between the nationality variable and the trait anxiety total score and "Cognitive Imagination". This relationship arises from the decrease in total anxiety scores as the national class $\mathrm{C}$ goes from $\mathrm{A}$ to $\mathrm{A}$. Again, as the national class goes from $\mathrm{C}$ to A, the use of "Cognitive Imagination" is positively affected. However, no statistically significant relationship was found between age, education level, mother education level, father education level and monthly income variables.

Keywords: Elite athlete, Karate, Imagery, Trait anxiety.

Öz: Bu araştırmanın temel amacı, elit karate sporcularının imgeleme kullanımları ve sürekli kaygı düzeyleri arasındaki ilişkinin incelenmesidir. Araştırmanın örneklem grubunu tesadüfi örneklem seçme yöntemiyle belirlenen 120 [ $\left.\mathrm{n}_{(\mathrm{erkek})}=61, \mathrm{n}_{(\mathrm{kad} ı)}=59\right]$ elit karate sporcusu oluşturmaktadır. Araştırmada veri toplama araçları olarak "Sporda İmgeleme Envanteri” ve "Sürekli Kaygı Envanteri” kullanılmıştır. Bu değişkenler parametrik testlerle sınanmış, aralarındaki ilişkinin belirlenmesi amacıyla da Pearson Momentler Çarpımı Korelasyon (r) Katsayısı tekniği kullanılmıştır. Araştırma sonuçlarına göre, yarışma alanı değişkenine ilişkin sürekli kaygı toplam puanı ve "Motivasyonel Özel İmgeleme" alt boyutu arasında anlamlı farklılıklar tespit edilmiştir. Katılımcıların anne eğitim durumu değişkeni ile "Motivasyonel Genel-Uyarılmışlık" ve "Motivasyonel Genel-Ustalık" alt boyutları arasında anlamlı farklılık tespit edilmiştir. Sürekli kaygı toplam puanı ile sporda imgeleme envanteri alt boyutlarından "Bilişsel İmgeleme" alt boyutunda düşük düzeyde anlamlı bir ilişki tespit edilmiştir. Millilik sınıfı ile sürekli kaygı toplam puanı değişkenlerine ilişkin yapılan korelasyon analizi neticesinde de düşük düzeyde anlamlı bir ilişki tespit edilmiştir. Yine millilik sınıfı değişkeni ilişkin analiz neticesinde sporda imgeleme envanteri alt boyutlarından "Bilişsel İmgeleme" alt boyutunda düşük düzeyde istatistikî açıdan anlamlı bir ilişki olduğu tespit edilmiştir. Sonuç olarak elit karate sporcularında imgeleme kullanımı ile sürekli kaygı toplam puanı arasında "Bilişsel İmgeleme" alt boyutunda düşük düzeyde anlamlı bir ilişki olduğu tespit edilmiştir.

Anahtar Kelimeler: Elit sporcu, Karate, İmgeleme, Sürekli kayg1. 


\section{Giriş}

Sportif etkinliklerin temelini, rekabet ve beraberinde getirmiş olduğu gerilim oluşturmaktadır (Filiz, 2002). Rekabet temelli bu aktivitelerde optimum performansa ulaşabilmek için yapılan fiziksel teknik ve taktik çalışmalarına ek olarak zihinsel açıdan üst noktaya erişilebilmek için de mental hazırlıklar yapılmalıdır (Bayraktar ve Kurtoğlu, 2009). Mental hazırlık sürecinde imgeleme çalı̧̧malarıyla yarışmada kullanılan fiziksel, teknik ve taktik becerilerini zihinde gerçekleştirmek gerekmektedir (Konter, 1998). Weinberg ve Gould (2015) imgelemeyi bir tür taklit ve benzeştirme olarak tanımlamışlardır. Bu çalışmalar gerçek yaşamın içerisinde yer alan duyusal bir deneyim (görmek, duymak vb.) ile benzerlik gösterir. Ancak deneyimin tümü zihinde gerçekleşir (Weinberg ve Gould, 2015).

Başarıyla sonuçlanan bir performansın imgelenmesi insan vücudunda fiziksel olarak kassal gerginlik sağlarken, zihinsel olarak kaygı düzeyinde olumlu etkilere sağlayabilir. İmgeleme çalışmaları aynı zamanda sporcuların zihinsel planlar oluşturmalarını ve bu planların başarılı bir şekilde gerçekleştirilmesiyle, kaygı düzeyini etkileyebilen durumlarla başa çıkmak için sporculara yardımcı olabilmesi amacıyla da kullanılabilir. Kaygı, kişinin içerisinde bulunduğu koşullara bağlı olarak gergin, sinirli ve evhamlı olma durumunun, uyarılmışlık düzeyi ile ilişkilendirilerek oluşan olumsuz duygu durumuna denir (Cheng, Hardy ve Markland, 2009). Kaygının bilişsel bir değişken olması nedeniyle, performansla ilgili kişisel kuşkuların artması ve reaksiyon üretememe gibi durumlar karşısında, kişinin performansına yönelik durumlarla etkili bir şekilde başa çıkabileceği senaryoları çalışması kaygı düzeyinde azalma sağlayabilir (Morris vd., 2005).

Yoğunlaşan antrenman ve yarışma şartları karate sporcularında zihinsel tükenme ve kaygı yüklü ruh hali gibi etkilere sebep olmaktadır (Aleshicheva, 2016). Kaygı, bir çok spor branşından sporcunun karşısına kaçınılmaz bir etken olarak çıktığı gibi karate sporcularının da düzeyi farklılık göstermekle birlikte karşılaştığı bir durumdur (Aksu, 2018; Sanığlu vd., 2017; Soltani ve Reddy, 2016). Sporcuların kaygı düzeyleri üzerinde etkisi olan en temel unsurlar arasında sporcunun tecrübesi yer almaktadır (amatör sporcu-elit sporcu). Bu anlamda elit düzeydeki sporcuların amatör sporculara kıyasla kaygı düzeylerinin daha yüksek olduğu bilinmektedir (Garcia vd., 2017). Weinberg, Seabourne ve Jackson (1981), karate sporunda kayg1 düzeyini en uygun seviyede tutabilmek için imgeleme çalışmalarının yardımcı olduğunu belirtmektedir. Bu bağlamda mevcut verilere dayanarak, elit karate sporcularında sürekli kaygı düzeyi ile imgeleme kullanım türlerini belirlemek ve bu iki değişkenin arasındaki ilişkiyi incelemek araştırmanın temel amaçlarıdır.

\section{Kavramsal Çerçeve}

\subsection{Karate}

Kelime anlamı silahsız mücadele sanatı olarak tanımlanan karate, "boş (kara)" ve "el (te)" sözlerinin birleşimi ile oluşmuştur (Kaya vd., 2017). Karate, rekabet düzeyinin gün geçtikçe arttığ bir Uzakdoğu sporudur. Bu branş aynı zamanda, Uluslararası Olimpiyat Komitesi'nin (IOC) onayı ile 2020 yılında Japonya'nın başkenti Tokyo'da düzenlenmesi planlanan olimpiyat oyunlarında yarışma hakkını ilk kez elde etmiştir (Hartz ve Moreno, 2018). Karate sporunun üç alt disiplini mevcuttur. Bunlar; kihon, kata ve kumitedir (Alkan ve Çolaklar, 2001). Kihon, bu sporun temeli niteliğindeki çalışma alanıdır. Kata disiplini, karate sporunda bulunan tüm tekniklerin estetik bir şekilde, koreografik olarak gerçekleştirilen hayali bir mücadele biçimidir. Kata disiplinin bir diğer özelliği de tüm dünya genelinde kabul görmesiyle birlikte önceden belirlenmiş bir dizi hareketlerden oluşmasıdır (Doria vd., 2009). Kumite disiplini ise, karate sporundaki mevcut tekniklerin yalın ve kombinasyon halinde, rekabete dayalı, belirli kurallara içerisinde, bazı (yaş, kilo ve cinsiyet) değişkenlerin göz ününde bulundurulduğu müsabaka durumudur (Chaabène vd., 2012). 


\subsection{Sürekli kaygı}

Kaygı, kişinin içerisinde bulunduğu koşullara bağlı olarak gergin, sinirli ve evhamlı olma durumunun, uyarılmışlık düzeyi ile ilişkilendirilerek oluşan olumsuz duygu durumuna denir (Cheng, Hardy ve Markland, 2009). Sürekli kaygı ise algılanan tehlikeli durumlara karşı bireyin sürekli olarak kaygılı reaksiyon göstermesiyle oluşan kaygı türü olarak tanımlanmaktadır (Özgüven, 1994). Kişi müdâhil olduğu durumları ve günlük yaşantıyı stres olarak yorumlayabilir veya stresli algılama eğilimi sergileyebilir bu durumlar da sürekli saygının göstergeleri arasındadır. Yapısal olarak kişinin sürekli kaygı yaşamasıyla birlikte kendisini tehdit içermeyen koşullarda bile tehlike altında hisseder (Speilberger, 1966).

\section{3. İmgeleme}

İmgeleme, birçok kaynakta çeşitli bakış açısıyla incelenmiştir. Weinberg ve Gould (2015), imgeleme uygulamalarını taklit yapmaya benzetmekle birlikte, gerçek hayatın içindeki duyusal olguların zihinsel olarak gerçekleştirilmesi şeklinde tanımlamışlardır. Burton ve Raedeke (2008) imgeleme kavramını, kişinin bir deneyimi zihninde yaratması ya da eski yaşanmış deneyimlerin yeniden yaratılması amacıyla tüm duyuların kullanması olarak tanımlamışlardır. White ve Hardy (1998) bir imgenin zihinde canlanması için tüm duyu organlarımızı kullanarak deneyimlememizin gerektiğini ifade ederken Moran (2004), imgeyi hissetmeksizin de algılanabileceği belirtmiştir. Davis (2015) ise imgelemenin kavramsal bir yetenek olduğunu savunmaktadır. Ayrıca bu yeteneği, var olmayan veya algılanamayan koşullarda (nesne, durum, olay vb.) zihinsel bir resim oluşturma olarak da tanımlamaktadır.

Bilişsel imgeleme, bir becerinin üst düzey bir performans ile uygulanmasını, hataların düzeltilmesini, strateji geliştirmeyi, oyun kurmayı öğrenmeyi ve uygulamayı ve benzeri bilişsel özellikleri zihinde oluşturmayı kapsamaktadır. Motivasyonel özel imgeleme, özel performans ile ilişkili hedefleri kapsayan imgelemedir. Örneğin bir sporcunun başarılı olması, iyi bir performans sergilemesinin ardından tebrik edildiğini zihninde canlandırması ve bu doğrultuda oluşan duygusal hisler gurur ve motivasyon kaynağını oluşturmaktadır.

Motivasyonel genel uyarılmışlık boyutunun adından da anlaşıldığı üzere bu imgeleme, sporcuların uyarılmışlı düzeyleri ile ilişkilidir. Bir sporcunun bu imgelemeyi kullanımının neticesinde uyarılmışlık düzeyini kontrol altına alması kolaylaşmaktadır. Bu zihinsel yetilerin kazanımının aynı zamanda olumsuz psikolojik değişkenler ile başa çıkılması noktasında kişiyi daha güçlü kıldıkları söylenebilir. Motivasyonel genel ustalık boyutunda ise motivasyonel becerilerin en üst düzeylere ulaştırılmak istenmesidir. Bu boyutta bahsi geçen ustalık kavramı ile sporcunun imgeleme çalışmalarıyla birlikte zihinsel gücünün ve kontrollünün arttığı yani ilgili konuda ustalık noktasına ulaştığı söylenir. Genel anlamda ustalığı içeren bu boyut, motivasyonel bakımdan da zihinsel yeterliliği sağlayarak olumsuz psikolojik durumlarla başa çıkma konusunda da güç kazandıkları bilinir (Kızıldağ ve Tiryaki, 2012).

\section{Yöntem}

\subsection{Araştırma Modeli}

Araştırmamızda elit karate sporcularında sürekli kaygı düzeyi ile imgeleme kullanım türlerini belirlemek ve bu iki değişkenin arasındaki ilişkiyi incelemek amaçlanmaktadır ve bu amaç doğrultusunda ilişkisel tarama modelinden faydalanılmıştır. İlişkisel tarama modeli, iki veya daha çok sayıda değişken arasındaki değişimin varlığı ya da derecesini belirlemek amaçlı bir araştırma modelidir (Karasar, 2013).

\subsection{Evren ve Örneklem Grubu}


Araştırma kapsamında veri toplama amaciyla Google Form veri tabanından faydalanılmıştır. Tüm katılımcılara ölçekler, e-mail aracılığıyla elektronik ortamda ulaştırılmıştır. Araştırmanın evrenini spor geçmişinde uluslararası seviyede yarışmalara katılan, Türk karate milli takımında yer alan ve karate branşında millilik belgesi (A, B ve C sınıfi) sahibi sporcular oluşturmaktadır. Örneklem grubu ise 2018-2019 sezonunda Büyükler Türkiye Karate Şampiyonasına katılan olan 120 karate sporcusundan oluşmaktadır.

\subsection{Veri Toplama Araçları}

\subsubsection{Kişisel Bilgi Formu}

Araştırmacı tarafından hazırlanan "Kişisel Bilgi Formu", 9 maddeden oluşarak araştırma grubunun demografik bilgilerine (cinsiyet, yaş, yarışma alanı ve kategorisi, spor yaşı, millilik sınıf, eğitim durumu, anne ve baba eğitim durumu ve aylık ortalama gelirlerini) ulaşmak için amacına uygun sorular içermektedir.

\subsubsection{Sporda İmgeleme Envanteri}

Hall, Mack, Paivio ve Hausenblas'ın 1998 yılında geliştirdiği "Sporda İmgeleme Envanterinin", Kızıldağ ve Tiryaki tarafından 2012 yılında Türkçe güvenirlik ve geçerlik çalışmaları yapılmıştır. Orijinal halinde 5 alt boyuta ve 30 maddeye sahip olan bu envanter, güvenirlik ve geçerlik çalışmasının neticesinde 4 alt boyut ve 21 madde olarak düzenlenmiştir. Envanterin yapı geçerliğini test edebilmek amacıyla verilere uygulanan faktör analizinin sonucunda 4 faktörün varyansın yaklaşık \%51'ini açıkladığı bulunmuştur. "Sporda İmgeleme Envanterinin" 4 alt boyutu bulunmaktadır. Bunlar; Bilişsel İmgeleme (.81), Motivasyonel Özel İmgeleme (.80), Motivasyonel Genel-Uyarılmışlık (.71) ve Motivasyonel Genel-Ustalıktır (.59) (Kızıldağ ve Tiryaki, 2012).

\subsubsection{Sürekli Kaygı Envanteri}

Sürekli Kaygı Envanteri, Spielberger (1970) tarafindan kişinin sürekli kaygı düzeyinin belirlenmesi için amaca uygun şekilde geliştirilmiştir. Türkçe çeviri, güvenirlik ve geçerlik çalışması ise Öner ve Le Compte (1983) tarafından yapılmıştır. 20 maddeden oluşan bu ölçeğin Alpha güvenirliğin 0.83 ile 0.87 arasındadır. Ortalama puanına göre, 20 - 35 puan aralığ "Düşük sürekli kaygı düzeyi”, 36 - 42 puan aralığı "Orta sürekli kaygı düzeyi” ve 43 - 80 puan aralığı ise "Yüksek sürekli kaygı düzeyi" olarak değerlendirilmektedir (Öner ve Le Compte 1983).

\subsection{Verilerin İstatistiksel Analizi}

Ölçekler aracıllğıyla elde edilmiş olan verilerin aritmetik ortalamaları ve standart sapmaları hesaplanarak araştırma grubunun imgeleme kullanımlarının ve sürekli kaygı düzeylerinin dağılımları tespit edilmiş̧ir. Bağımsız değişkenler ile imgeleme kullanımları ve sürekli kaygı toplam puanları parametrik testlerden One-Way ANOVA ve Tukey tabi tutulmuştur. Aynı zamanda iki değişkenli karşılaştırmalar için bağımsız t-Testi'nden yararlanılmıştır. Araştırma grubunun imgeleme kullanımları ile sürekli kaygı toplam puanlarının arasındaki ilişkinin belirlenmesi amacıyla da Pearson Momentler Çarpımı Korelasyon (r) Katsayısı tekniği kullanılmıştır. Yapılan analizlerin sonucunda anlamlılık düzeyi " 0.05 ” oranında alınmıştır $(\mathrm{p}<0.05)$. 


\section{Bulgular}

Tablo 1: Araştırma grubundan elde edilen verilerin cinsiyet değişkenine bağl1 olarak t-testi sonuçları.

\begin{tabular}{|c|c|c|c|c|c|c|c|}
\hline & Cinsiyet & $\mathrm{n}$ & Ort. & Ss. & $\mathrm{t}$ & Sd. & $\mathrm{p}$ \\
\hline \multirow{2}{*}{ Sürekli Kayg1 Toplam Puanı } & Kadın & 59 & 45,88 & 3,68 & \multirow[b]{2}{*}{1,258} & \multirow[b]{2}{*}{118} & \multirow[b]{2}{*}{, 211} \\
\hline & Erkek & 61 & 44,96 & 4,24 & & & \\
\hline \multirow[b]{2}{*}{ Bilişsel İmgeleme } & Kadın & 59 & 5,50 & ,96 & \multirow[b]{2}{*}{,- 421} & \multirow[b]{2}{*}{118} & \multirow[b]{2}{*}{674} \\
\hline & Erkek & 61 & 5,58 & 1,01 & & & \\
\hline \multirow{2}{*}{$\begin{array}{l}\text { Motivasyonel } \\
\text { Özel İmgeleme }\end{array}$} & Kadın & 59 & 5,74 & 1,15 & \multirow[b]{2}{*}{1,505} & \multirow[b]{2}{*}{118} & \multirow[b]{2}{*}{, 135} \\
\hline & Erkek & 61 & 5,39 & 1,39 & & & \\
\hline \multirow{2}{*}{$\begin{array}{c}\text { Motivasyonel } \\
\text { Genel - Uyarılmışlık }\end{array}$} & Kadın & 59 & 4,64 & 1,28 & \multirow[b]{2}{*}{$-1,605$} & \multirow[b]{2}{*}{118} & \multirow[b]{2}{*}{, 111} \\
\hline & Erkek & 61 & 5,02 & 1,30 & & & \\
\hline \multirow{2}{*}{$\begin{array}{c}\text { Motivasyonel } \\
\text { Genel - Ustalık }\end{array}$} & Kadın & 59 & 5,92 & 1,02 & \multirow[b]{2}{*}{,883 } & \multirow[b]{2}{*}{118} & \multirow[b]{2}{*}{, 379} \\
\hline & Erkek & 61 & 5,72 & 1,41 & & & \\
\hline
\end{tabular}

Tablo 1'e göre cinsiyet değişkenine bağlı sürekli kaygı envanterinden elde edilen toplam puanlar karşılaştırıldığında kadın ve erkek katılımcıların toplam puanları arasında istatistikî açıdan anlamlı bir farklılığa rastlanmamıştır $(\mathrm{p}<0.05)$. Fakat kadın katılımcıların sürekli kaygı envanteri toplam puanları " 45,88 " olarak belirlenirken, erkek katılımcıların sürekli kaygı envanteri toplam puanları ise " 44,96 "dir. Elde edilen bu veriler neticesinde, katılımcıların sürekli kaygı envanteri toplam puanlarının 43-80 puan aralığında yer almasıyla birlikte "Yüksek Sürekli Kaygı Düzeyi" olarak değerlendirilmesi anlamına gelmektedir. Cinsiyet değişkenine bağlı sporda imgeleme envanterinin alt boyutlarından elde edilen ortalama puanlar karşılaştırıldığında kadın ve erkek katılımcıların ortalama puanları arasında istatistikî açıdan anlamlı bir farklılığa rastlanmamıştır $(\mathrm{p}>0.05)$.

Tablo 2: Araştırma grubundan elde edilen verilerin spor yaşı değişkenine bağlı olarak karşılaştırılmasına yönelik ANOVA sonuçları.

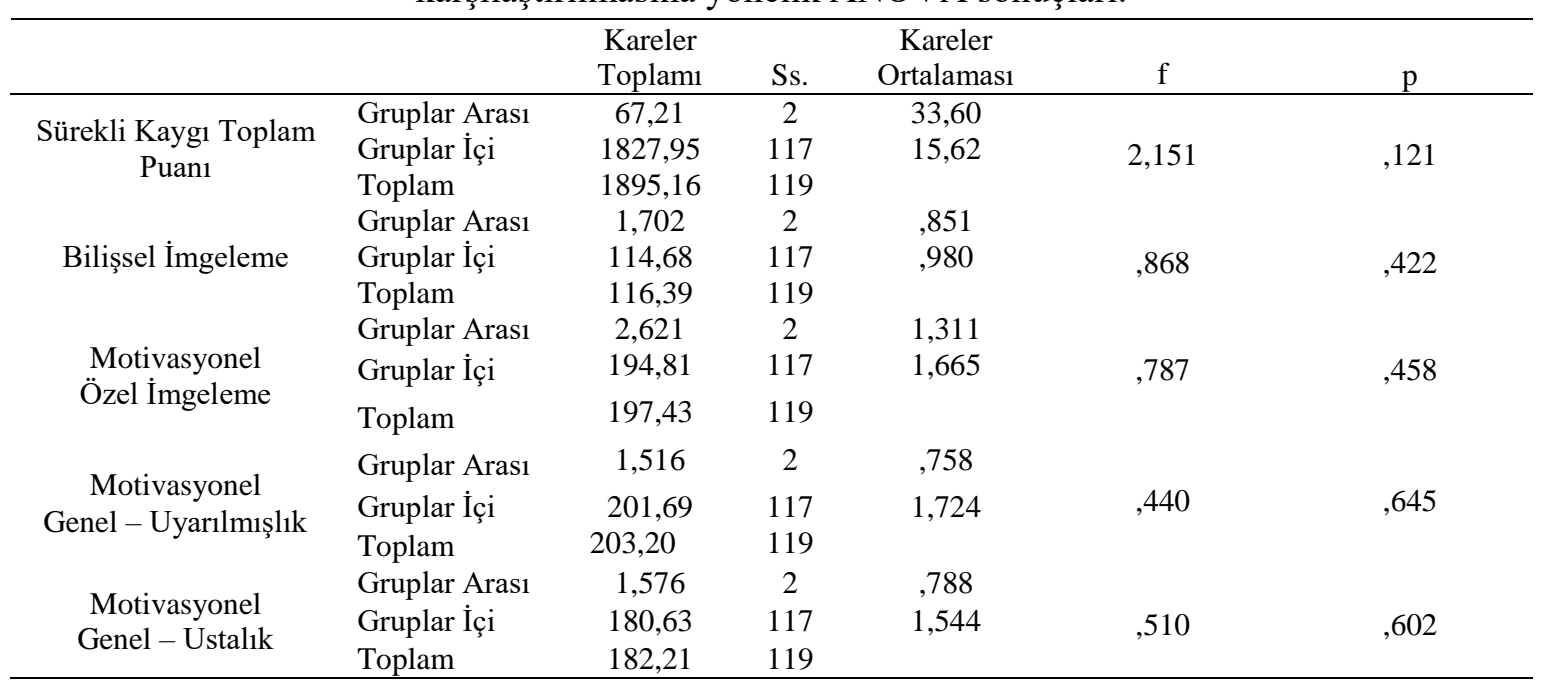

Tablo 2 incelendiğinde, elde edilen verilerin spor yaşı değişkenine bağlı olarak sürekli kaygı envanterinin toplam puanları arasında istatistikî açıdan anlamlı bir farklılı̆̆a rastlanmamıştır $(\mathrm{p}>0.05)$. Sporda imgeleme envanterinin alt boyutlarında da katılımcıların ortalama puanları arasında istatistikî açıdan anlamlı bir farklılığa rastlanmamıştır ( $\mathrm{p}>0.05)$. 
Tablo 3: Araştırma grubundan elde edilen verilerin yarışma alanı değişkenine bağlı t-testi sonuçları.

\begin{tabular}{|c|c|c|c|c|c|c|c|}
\hline & $\begin{array}{c}\text { Yarışma } \\
\text { Alanı }\end{array}$ & $\mathrm{n}$ & Ort. & Ss. & $\mathrm{t}$ & Sd. & $\mathrm{p}$ \\
\hline \multirow{2}{*}{ Sürekli Kaygı Toplam Puanı } & Kumite & 90 & 44,92 & 3,681 & \multirow[b]{2}{*}{$-2,397$} & \multirow[b]{2}{*}{118} & \multirow[b]{2}{*}{, $018 *$} \\
\hline & Kata & 30 & 46,90 & 4,551 & & & \\
\hline \multirow{2}{*}{ Bilişsel İmgeleme } & Kumite & 90 & 5,48 & 1,033 & \multirow[b]{2}{*}{$-1,216$} & \multirow[b]{2}{*}{118} & \multirow[b]{2}{*}{,226 } \\
\hline & Kata & 30 & 5,73 & ,828 & & & \\
\hline \multirow{2}{*}{$\begin{array}{l}\text { Motivasyonel } \\
\text { Özel İmgeleme }\end{array}$} & Kumite & 90 & 5,41 & 1,388 & \multirow[b]{2}{*}{$-2,212$} & \multirow[b]{2}{*}{118} & \multirow[b]{2}{*}{, $029 *$} \\
\hline & Kata & 30 & 6,00 &, 788 & & & \\
\hline \multirow{2}{*}{$\begin{array}{c}\text { Motivasyonel } \\
\text { Genel - Uyarılmışlık }\end{array}$} & Kumite & 90 & 4,77 & 1,379 & \multirow[b]{2}{*}{,- 947} & \multirow[b]{2}{*}{118} & \multirow[b]{2}{*}{, 345} \\
\hline & Kata & 30 & 5,03 & 1,054 & & & \\
\hline \multirow{2}{*}{$\begin{array}{c}\text { Motivasyonel } \\
\text { Genel - Ustalık }\end{array}$} & Kumite & 90 & 5,71 & 1,301 & \multirow[b]{2}{*}{$-1,703$} & \multirow[b]{2}{*}{118} & \multirow[b]{2}{*}{,091 } \\
\hline & Kata & 30 & 6,15 & 965 & & & \\
\hline
\end{tabular}

Tablo 3'e göre, yarışma alanı değişkenine bağlı sürekli kaygı envanterinden elde edilen toplam puanlar karşılaştırıldığında kata ve kumite sporcularının toplam puanları arasında istatistikî açıdan anlamlı bir farklılığa rastlanmıştır $(\mathrm{p}<0.05)$. Ortalama puanlar incelendiğinde kata sporcularının sürekli kaygı toplam puanlarının kumite sporcularına oranla daha yüksek olduğu görülmektedir. Yarışma alanı değişkenine bağlı sporda imgeleme envanterinin alt boyutlarından elde edilen ortalama puanlar incelendiğinde yalnızca "Motivasyonel Özel İmgeleme" alt boyutunda anlamlı farklılığa rastlanmıştır $(\mathrm{p}<0.05)$ ve bu farklılık kata sporcularının kumite sporcularına oranla bu alt boyutu daha fazla kullanmasindan kaynaklanmaktadır.

Tablo 4: Araştırma grubundan elde edilen verilerin eğitim durumu değişkenine bağlı olarak karșılaștırılmasına yönelik ANOVA sonuçları.

\begin{tabular}{|c|c|c|c|c|c|c|}
\hline & & $\begin{array}{l}\text { Kareler } \\
\text { Toplamı }\end{array}$ & Ss. & $\begin{array}{c}\text { Kareler } \\
\text { Ortalamas1 }\end{array}$ & $\mathrm{f}$ & $\mathrm{p}$ \\
\hline \multirow{3}{*}{$\begin{array}{c}\text { Sürekli Kaygı Toplam } \\
\text { Puanı }\end{array}$} & Gruplar Arası & 80,92 & 2 & 40,46 & \multirow{3}{*}{2,609} & \multirow{3}{*}{, 07} \\
\hline & Gruplar İçi & 1814,24 & 117 & 15,50 & & \\
\hline & Toplam & 1895,16 & 119 & & & \\
\hline \multirow{3}{*}{ Bilişsel İmgeleme } & Gruplar Arası & 5,118 & 2 & 2,559 & \multirow{3}{*}{2,691} & \multirow{3}{*}{, 072} \\
\hline & Gruplar İçi & 111,27 & 117 & ,951 & & \\
\hline & Toplam & 116,39 & 119 & & & \\
\hline \multirow{3}{*}{$\begin{array}{c}\text { Motivasyonel } \\
\text { Özel İmgeleme }\end{array}$} & Gruplar Aras1 & 3,151 & 2 & 1,575 & \multirow{3}{*}{,949 } & \multirow{3}{*}{, 390} \\
\hline & Gruplar İçi & 194,28 & 117 & 1,661 & & \\
\hline & Toplam & 197,43 & 119 & & & \\
\hline \multirow{3}{*}{$\begin{array}{c}\text { Motivasyonel } \\
\text { Genel - Uyarılmışlık }\end{array}$} & Gruplar Arası & 6,923 & 2 & 3,461 & \multirow{3}{*}{2,063} & \multirow{3}{*}{, 132} \\
\hline & Gruplar İçi & 196,28 & 117 & 1,678 & & \\
\hline & Toplam & 203,20 & 119 & & & \\
\hline \multirow{3}{*}{$\begin{array}{c}\text { Motivasyonel } \\
\text { Genel - Ustalık }\end{array}$} & Gruplar Arası & ,933 & 2 &, 467 & \multirow{3}{*}{, 301} & \multirow{3}{*}{, 741} \\
\hline & Gruplar İçi & 181,28 & 117 & 1,549 & & \\
\hline & Toplam & 182,21 & 119 & & & \\
\hline
\end{tabular}

Tablo 4'deki veriler incelendiğinde, elde edilen verilerin katılımcıların eğitim durumu değişkenine bağl1 olarak sürekli kaygı envanterinin toplam puanları arasında istatistikî açıdan anlamlı bir farklılığa rastlanmamıştır $(\mathrm{p}>0.05)$. Sporda imgeleme envanterinin alt boyutlarında da katılımcıların ortalama puanları arasında istatistikî açıdan anlamlı bir farklılığa rastlanmamıştır $(\mathrm{p}>0.05)$. 
Tablo 5: Araştırma grubundan elde edilen verilerin anne eğitim durumu değişkenine bağlı olarak karşılaştırılmasına yönelik ANOVA sonuçları.

\begin{tabular}{|c|c|c|c|c|c|c|}
\hline & & $\begin{array}{c}\text { Kareler } \\
\text { Toplamı } \\
\end{array}$ & Ss. & $\begin{array}{c}\text { Kareler } \\
\text { Ortalamas1 } \\
\end{array}$ & $\mathrm{f}$ & $\mathrm{p}$ \\
\hline \multirow{3}{*}{$\begin{array}{c}\text { Sürekli Kaygı Toplam } \\
\text { Puanı }\end{array}$} & Gruplar Aras1 & 29,35 & 2 & 14,67 & \multirow{3}{*}{,920 } & \multirow{3}{*}{,401 } \\
\hline & Gruplar İçi & 1865,81 & 117 & 15,94 & & \\
\hline & Toplam & 1895,16 & 119 & & & \\
\hline \multirow{3}{*}{ Bilişsel İmgeleme } & Gruplar Aras1 & 3,651 & 2 & 1,82 & \multirow{3}{*}{1,894} & \multirow{3}{*}{, 155} \\
\hline & Gruplar İçi & 112,73 & 117 & ,964 & & \\
\hline & Toplam & 116,39 & 119 & & & \\
\hline \multirow{3}{*}{$\begin{array}{c}\text { Motivasyonel } \\
\text { Özel İmgeleme }\end{array}$} & Gruplar Arası & 2,267 & 2 & 1,134 & \multirow{3}{*}{,680 } & \multirow{3}{*}{, 509} \\
\hline & Gruplar İçi & 195,17 & 117 & 1,668 & & \\
\hline & Toplam & 197,43 & 119 & & & \\
\hline \multirow{3}{*}{$\begin{array}{c}\text { Motivasyonel } \\
\text { Genel - Uyarılmışlık }\end{array}$} & Gruplar Aras1 & 12,780 & 2 & 6,390 & \multirow{3}{*}{3,926} & \multirow{3}{*}{, $022 *$} \\
\hline & Gruplar İçi & 190,42 & 117 & 1,628 & & \\
\hline & Toplam & 203,20 & 119 & & & \\
\hline \multirow{3}{*}{$\begin{array}{c}\text { Motivasyonel } \\
\text { Genel - Ustalık }\end{array}$} & Gruplar Arası & 13,52 & 2 & 6,761 & \multirow{3}{*}{4,690} & \multirow{3}{*}{,011* } \\
\hline & Gruplar İçi & 168,69 & 117 & 1,442 & & \\
\hline & Toplam & 182,21 & 119 & & & \\
\hline
\end{tabular}

Tablo 5.'e göre, elde edilen verilerin katılımcıların anne eğitim durumu değişkenine bağlı olarak sürekli kaygı envanterinin toplam puanları arasında istatistikî açıdan anlamlı bir farklılığa rastlanmamıştır ( $>0.05)$. Sporda imgeleme envanterinin de "Bilişsel İmgeleme" ve "Motivasyonel Özel İmgeleme" alt boyutlarında anlamlı bir farklılığa rastlanmamıştır $(p>0.05)$. Fakat "Motivasyonel Özel İmgeleme" ve "Motivasyonel Genel Ustalık" alt boyutlarında anlamlı farklılığa rastlanmıştır $(\mathrm{p}<0.05)$. Farklılı̆̆ın hangi gruplar arasında olduğunu tespit etmek amaçlı yapılan Tukey testine göre ise; sporcuların anne eğitim durumu değişkenine göre "İlkokul/Ortaokul" mezunu olanlar ile "Lise" mezunu olanlar arasında önemli bir fark olduğu tespit edilmiştir. Bu farkın anne eğitim durumu "Lise" mezunu olan katılımcıların Motivasyonel Genel Uyarılmışlık ve Motivasyonel Genel Ustalık alt boyutlarını daha fazla kullanmasından kaynaklandığı görülmektedir.

Tablo 6: Araştırma grubundan elde edilen verilerin baba eğitim durumu değişkenine bağlı olarak karşılaştırılmasına yönelik ANOVA sonuçları.

\begin{tabular}{|c|c|c|c|c|c|c|}
\hline & & $\begin{array}{c}\text { Kareler } \\
\text { Toplamı }\end{array}$ & Ss. & $\begin{array}{c}\text { Kareler } \\
\text { Ortalamas1 } \\
\end{array}$ & $\mathrm{f}$ & $\mathrm{P}$ \\
\hline \multirow{3}{*}{$\begin{array}{c}\text { Sürekli Kaygı Toplam } \\
\text { Puanı }\end{array}$} & Gruplar Aras1 & 20,37 & 2 & 10,18 & \multirow{3}{*}{,636 } & \multirow{3}{*}{, 531} \\
\hline & Gruplar İçi & 1874,79 & 117 & 16,02 & & \\
\hline & Toplam & 1895,16 & 119 & & & \\
\hline \multirow{3}{*}{ Bilişsel İmgeleme } & Gruplar Arası & 3,249 & 2 & 1,625 & \multirow{3}{*}{1,680} & \multirow{3}{*}{,191 } \\
\hline & Gruplar İçi & 113,14 & 117 & ,967 & & \\
\hline & Toplam & 116,39 & 119 & & & \\
\hline \multirow{3}{*}{$\begin{array}{c}\text { Motivasyonel } \\
\text { Özel İmgeleme }\end{array}$} & Gruplar Arası & 2,618 & 2 & 1,309 & \multirow{3}{*}{, 786} & \multirow{3}{*}{, 458} \\
\hline & Gruplar İçi & 194,82 & 117 & 1,665 & & \\
\hline & Toplam & 197,43 & 119 & & & \\
\hline \multirow{3}{*}{$\begin{array}{c}\text { Motivasyonel } \\
\text { Genel - Uyarılmışlık }\end{array}$} & Gruplar Aras1 & ,339 & 2 &, 170 & \multirow{3}{*}{,098 } & \multirow{3}{*}{,907 } \\
\hline & Gruplar İçi & 202,86 & 117 & 1,734 & & \\
\hline & Toplam & 203,20 & 119 & & & \\
\hline \multirow{3}{*}{$\begin{array}{c}\text { Motivasyonel } \\
\text { Genel - Ustalık }\end{array}$} & Gruplar Aras1 & 20,373 & 2 & 10,18 & \multirow{3}{*}{, 764} & \multirow{3}{*}{,468 } \\
\hline & Gruplar İçi & 1874,79 & 117 & 16,02 & & \\
\hline & Toplam & 1895,16 & 119 & & & \\
\hline
\end{tabular}


Tablo 6'da görüldüğü üzere elde edilen verilerin katılımcıların baba eğitim durumu değişkenine bağlı olarak sürekli kaygı envanterinin toplam puanları arasında istatistikî açıdan anlamlı bir farklılığa rastlanmamıştır ( $>0.05)$. Sporda imgeleme envanterinin alt boyutlarında da katılımcıların ortalama puanları arasında istatistikî açıdan anlamlı bir farklılığa rastlanmamıştır $(\mathrm{p}>0.05)$.

Tablo 7: Katılımcıların bazı değişkenlerine göre sürekli kaygı envanteri toplam puanı ve sporda imgeleme envanterinin alt boyutları arasındaki korelasyon analizi sonuçları.

\begin{tabular}{ccccccc}
\hline & & Sürekli Kayg1 & $\begin{array}{c}\text { Bilişsel } \\
\text { Toplam Puanı }\end{array}$ & $\begin{array}{c}\text { Motivasyonel } \\
\text { Özel } \\
\text { İmgeleme }\end{array}$ & $\begin{array}{c}\text { Motivasyonel } \\
\text { Genel } \\
\text { Imgeleme }\end{array}$ & $\begin{array}{c}\text { Motivasyonel } \\
\text { Genel } \\
\text { Ustalı }\end{array}$ \\
\hline Yaş & $\mathrm{r}$ &,- 085 &, 006 &,- 150 &,- 016 &,- 105 \\
& $\mathrm{p}$ &, 355 &, 944 &, 103 &, 863 &, 255 \\
Sürekli Kayg1 & $\mathrm{r}$ & 1 & $\mathbf{- , 2 0 0}\left(^{*}\right)$ &, 066 &, 143 &,- 132 \\
Toplam Puanı & $\mathrm{p}$ & & $\mathbf{, 0 2 8}$ &, 473 &, 120 &, 151 \\
Eğitim Durumu & $\mathrm{r}$ &,- 111 &,- 005 &,- 104 &,- 097 &,- 030 \\
& $\mathrm{p}$ &, 229 &, 961 &, 256 &, 292 &, 749 \\
Anne Eğitim & $\mathrm{r}$ &,- 023 &, 032 &,- 080 &, 024 &,- 021 \\
Durumu & $\mathrm{p}$ &, 807 &, 725 &, 386 &, 794 &, 819 \\
Baba Eğitim & $\mathrm{r}$ &,- 020 &,- 016 &, 019 &,- 100 &,- 002 \\
Durumu & $\mathrm{p}$ &, 825 &, 859 &, 836 &, 276 &, 986 \\
Aylik Gelir & $\mathrm{r}$ &,- 097 &, 125 &,- 166 &,- 074 &,- 118 \\
& $\mathrm{p}$ &, 290 &, 172 &, 070 &, 419 &, 199 \\
Millilik Sinıfi & $\mathrm{r}$ & $\mathbf{- , 1 9 8}\left(^{*}\right)$ & $\mathbf{, 1 8 9}(*)$ &, 053 &,- 135 &, 067 \\
& $\mathrm{p}$ & $\mathbf{, 0 3 0}$ & $\mathbf{, 0 3 9}$ &, 568 &, 141 &, 467 \\
\hline
\end{tabular}

Tablo 7'ye göre elit karate sporcularının sürekli kaygı toplam puanları ile sporda imgeleme envanterinin "Bilişsel İmgeleme" arasında düşük düzeyde ilişki tespit edilmiştir. Bu ilişki, katılımcıların sürekli kaygı puanlarının bilişsel imgeleme kullanımına bağlı azaldığını ifade etmektedir. Millilik sınıfı değişkeni ile sürekli kaygı toplam puanı ve "Bilişsel İmgeleme" arasında da düşük düzeyde ilişki tespit edilmiştir. Bu ilişki millilik sınıfı C'den A'ya doğru gidildikçe sürekli kaygı toplam puanlarının azalmasından kaynaklanmaktadır. Yine millik sınıfı C'den A'ya doğru gidildikçe "Bilişssel İmgeleme" kullanımı pozitif yönde etkilenmektedir. Fakat yaş, eğitim durumu, anne eğitim durumu, baba eğitim durumu ve aylık gelir değişkenleri arasında istatistik açıdan anlamlı bir ilişkiye rastlanmamıştır.

\section{Tartışma ve Sonuç}

Cinsiyet değişkenine göre elit karate sporcularının sürekli kaygı toplam puanları arasında anlamlı bir farklılık olmamakla beraber "yüksek sürekli kaygı" düzeyine sahip oldukları belirlenmiştir. Soltani ve Reddy'nin (2013) araştırma sonuçlarına göre elit karate sporcularının kaygı düzeyle anlamlı düzeyde yüksek bulunmuştur ve bu sonuçta bizim araştırma sonuçlarımızla benzerlik gösterdiği söylenebilir. Araştırma verilerinin bu yönde dağılım göstermesinin nedeni olarak, karate sporcularının olimpiyat oyunlarında ilk kez yer alacak olmasıyla birlikte, sporcuların katıldıkları eleme yarışmaları ve olimpiyat oyunlarında yarışma hakkı elde etmek için kota mücadelesi verdikleri müsabakaların (Premier Lig, Seri A Turnuvas1, Avrupa ve Dünya Şampiyonaları) zorluk dereceleri ile ilişkili olabileceği düşünülmektedir. 
Elit kata sporcularının, kumite sporcularına kıyasla sürekli kaygı toplam puanlarının anlamlı düzeyde daha yüksek olduğu ve "Motivasyonel Özel İmgeleme" alt boyutunu daha yoğun kullandıkları araştırma sonuçlarımız arasında yer almaktadır. Adler (2003), bu veriyi destekler nitelikte kata disiplininin kumiteye oranla saldırganlık düzeyinin az olması ve temas içermemesine bağlı olarak daha sakin bir alan olduğunu ifade etmiştir. Ancak kata disiplininde yarışan sporcuların sürekli kaygı toplam puanlarının yüksek olduğunu da ifade etmiştir. Kata sporcularının kayg1 düzeylerinin yüksek olmasının temelinde kata müsabakalarının gereksinimlerinin yattığı düşünülmektedir. Fajar, Saputra ve Mulyana'nın (2018) elit ve elit altı karate sporcularının örneklem grubunu oluşturduğu araştırması sonucunda elit kata sporcularının en çok imgeleme kullanan grup olduğunu ve bunun nedeni olarak yüksek teknik performansa ek olarak yüksek uyarılmış düzeyine ihtiyaç duyduklarına bağlı olduğunu düşünmüşlerdir.

Eğitim durumu değişkenine bağlı elit karate sporcularının sürekli kaygı toplam puanları ve imgeleme kullanımlarına yönelik anlamlı bir sonuca ulaşılmamıştır. Kolayiş'in (2012) araştırma sonuçları, karate sporcularının eğitim durumunun sürekli kaygı düzeylerini olumlu ya da olumsuz etkilemediği yönündedir. Yalçın'ın (2018) profesyonel futbol sporcuları ile gerçekleştirdiği araştırma sonuçları da sporcuların eğitim durumu ile imgeleme kullanımı arasında anlamlı bir farklılığa rastlamamıştır. Bu verilere dayanarak söylenebilir ki; kaygı düzeyi ve imgeleme kullanımının kişinin eğitim durumu ile doğrudan bir bağlantısı olmamakla birlikte bireysel farklı1ıklara dayalı olarak değişiklik gösterebileceği düşünülmektedir.

Sporda imgeleme envanterinin "Bilişsel İmgeleme" alt boyutunun sürekli kaygı envanteri toplam puanlarını negatif yönde etkilediği sonucu gözlemlenmektedir. Elde ettiğimiz bu veriyi destekleyecek nitelikte Weinberg, Seabourne ve Jackson (1981), araştırmaları kapsamında elit karate sporcuları ile 6 haftalık imgeleme çalışmasının sonucunda anlamlı oranda sürekli kaygı düzeylerinde azalma olduğu sonucuna ulaşmışlardır. Birçok araştırma sporda imgeleme kullanımının sürekli kaygı düzeyinde azalmaya yardımcı olduğunu sonucunu vurgulamıştır (Güvendi, 2015; Peker, 2012).

Millilik sınıfı değişkeni ile sürekli kaygı envanteri toplam puanları arasında düşük düzeyde istatistikî açıdan negatif yönlü anlamlı bir ilişki olduğu ve "Bilişsel İmgeleme" alt boyutu ile pozitif yönlü anlamlı bir ilişki olduğu sonucuna ulaşılmıştır. Öz, Şirin ve Döşyılmaz'ın (2017) elit güreş sporcuları ile gerçekleştirdikleri araştırmada, millilik durumları ile imgeleme envanteri alt boyutlarından "Motivasyonel Genel Uyarılmışlık" arasında anlamlı düzeyde ilişki olduğunu belirlemişlerdir. Altıparmak (2019) ise temaslı ve temassız spor gruplarından sporcuların millilik durumlarına bağlı olarak "Bilişsel İmgeleme" alt boyutunda anlamlı ilişki olduğunu tespit etmiştir. Sonuç olarak elit karate sporcularının imgeleme kullanımları ve sürekli kaygı toplam puanları arasında "Bilişsel İmgeleme" alt boyutunda düşük düzeyde bir ilişki olduğu tespit edilmiştir.

\section{Kaynakça}

Adler, U. B. (2003). Karate and mental health: Can the practice of a martial art reduce aggressive tendencies?. ETD Collection for Pace University.

Aksu, O. (2018). Karate sporcularının sürekli kaygı düzeyleri, duygusal zekâ ve kişiliközelliklerinin çeşitli değişkenlere göre karşılaş̧ırılması, Bartın Üniversitesi, Eğitim Bilimleri Enstitüsü, Beden Eğitimi ve Spor Öğretmenliği Anabilim Dalı, Yüksek Lisans Tezi.

Aleshicheva, A. (2016). Psychological health of professional athletes involved in extreme sports, https://www.researchgate.net/publication/305741148, s. 41. 
Altıparmak, Y. (2019). Imgeleme ve kişilik: Temaslı ve temassız spor branşlartyla uğraşan sporcular üzerine bir araştırma. Ege Üniversitesi, Sağlık Bilimleri Enstitüsü, Sporda PsikoSosyal Alanlar Anabilim Dal1, s. 17-34.

Bayraktar, B. \& Kurtoğlu, M. (2009). Sporda performans, etkili faktörler, değerlendirilmesi ve artırılması. Klinik Gelişim, s. 16-24.

Cheng, W. N. K., Hardy, L. \& Markland, D. (2009). Toward a three-dimensionalconceptualization of performance anxiety: Rational and initial measurement development, Psychology of Sport and Exercise, s. 271.

Fajar, M., Saputra, Y. M. \& Mulyana, M. (2018). Imagery model and sport confidence on karate kata motion skills. In Proceedings of the 2nd International Conference on Sports Science, Health and Physical Education s. 111-116.

Filiz, K. (2002). Sporun tanımlanması ve kapsamının belirlenmesi üzerine bir çalışma, Gazi Ĕgitim Fakültesi Dergisi, 22(2), s. 203-211.

Garcia, V., Quinonez, O. \& Romo, E. (2017). Pre-competitive anxiety in high-performance, amateur and novice karate. Revista Cubana de Investigaciones Biomédicas. 36(2), 239-247.

Güvendi, B. (2015). Elit akademi ligi futbolcularında imgeleme ve kaygı ilişkisinin incelenmesi. Gazi Üniversitesi, Eğitim Bilimleri Enstitüsü, Yüksek Lisans Tezi.

Hall, C. R., Mack, D., Paivio, A. \& Hausenblas, H. (1998). Imagery use by athletes: Development of the sport imagery questionnaire. International Journal of Sport Psychology, 29, s. 73-89.

Kızıldağ, E. \& Tiryaki, M., Ş. (2012). Sporda imgeleme envanterinin Türk sporcular için uyarlanmas1, Hacettepe Üniversitesi Spor Bilimleri Dergisi, 23 (1), 13-23.

Kolayiş, H. (2012). Using EEG biofeedback in karate: The relationship among anxiety, motivation and brain waves. Archives of Budo, 8(1), s. 13-18.

Konter, E. (1998). Sporda psikolojik hazırlı̆̆ın teori ve pratiği: Bağırgan Yayınevi.

Morris, T., Spittle, M. \& Watt, P. A. (2005). Imagery in sport. Human Kinetics.

Öner, N. \& Le Compte, A. (1983). Durumluk-Sürekli kaygı envanteri el kitabı. Boğaziçi Üniversitesi Yayınları.

Öz, G., Şirin, Y. \& Döşyılmaz, E. (2017). Tohm projesi kapsamındaki üst düzey güreşçilerin sporda imgeleme biçimlerinin incelenmesi. 15. Uluslararası Spor Bilimleri Kongresi, 15-18 Kasım, Antalya. Bildiri Kitabı.

Özgüven, İ. E. (1994). Psikolojik testler. PDREM Yayınları.

Peker, N. (2012). Özdenetimin sporcuların performans ve kaygı düzeylerindeki rolü. İstanbul Ticaret Universitesi Sosyal Bilimler Dergisi, 21(1), 39-48.

Sanığlu, A., Ülker, M. \& Sanığlu Tanış, Z. (2017). The effect of trait anxiety on success in individual athletes. Turkish Journal of Sport and Exercise. 19(2), 289-295.

Soltani, H. \& Reddy, K. S. (2013). Comparative analysis of competitive state anxiety among elite and non-elite karate athletes. Advances in Environmental Biology, 7(7), 1244-1248.

Weinberg, R. S. \& Gould, D. (2015). Spor ve egzersiz psikolojisinin temelleri. Human Kinetics, Ankara: Nobel Akademik Yayıncılık, 6. Baskı.

Weinberg, R. S., Seabourne, T. G. \& Jackson, A. (1981). Effects of visuo-motor behavior rehearsal, relaxation, and 1magery on karate performance, Journal Of Sport Psychology, 3(3), 228-238. 
Yalçın, İ. (2018). Profesyonel futbolcularda zihinde canlandırma ile öz güven arasındaki ilişkinin araştırılması. Sakarya Üniversitesi, Eğitim Bilimleri Enstitüsü, Beden Eğitimi ve Spor Eğitimi Anabilim Dal, Doktora Tezi. 